\title{
Evolving artificial intelligence and robotics in medicine, evolving European law. Comparative remarks based on the surgery litigation
}

Maastricht Journal of European and Comparative Law 202I, Vol. 28(6) 805-833

(C) The Author(s) 2021

Article reuse guidelines: sagepub.com/journals-permissions DOI: 10.1 I77// 023263X21 I042470 maastrichtjournal.sagepub.com

@SAGE

\section{Giorgia Guerra (D)}

\begin{abstract}
This article discusses key and critical tort law issues that have arisen from artificial intelligence and robotic medical applications. It aims at addressing the most recent European regulatory trajectories - ultimately traced by the Proposal for the Artificial Intelligence Act April 21 2021 - starting from the study of the legal issues that stemmed from the instructive experience of the US litigation on robotic surgery, which was foregoing on account of its cutting-edge and accelerated enhancement of the field. The recognition and analysis of the criticalities about products' malfunctioning as well as the focus on other producers' duties will lead the reader to reflect on the suitability of the legal rules planned by the European Authorities on the ground of the empirical features of the new step of technological progress in the field in question.
\end{abstract}

\section{Keywords}

Comparative tort law, empirical research, European regulation, law and technology, medical law, US litigation

\section{Introduction}

In the 'dynamic' European legal landscape concerning product regulation and liability for artificial intelligence applications in medicine - which this introduction will describe - this article aims at pointing out which insights and lessons have been illustrated by the US case-law on robotic surgery, given its prominent meaning.

Assistant Professor in Comparative Private Law, Department of Legal Sciences, University of Verona, Verona, Italy

Corresponding author:

Giorgia Guerra, Assistant Professor in Comparative Private Law, University of Verona, Department of Legal Sciences, Italy. Email: giorgia.guerra@univr.it 
As alluded to above, during the last two years the European Regulatory framework in the field of AI has provided a set of benchmarks for addressing the complex enabling ecosystem and the features of autonomous decision-making. They have been shown to be particularly keen on reflecting on the suitability of current safety and liability regimes, as highly sophisticated AI technologies may present new safety risks for users when embedded. ${ }^{1}$

Besides all the crucial domains for AI developments, legal issues are particularly debated with regard to near-future applications in medicine and healthcare, even in the perspective of fostering personalized medicine. In this perspective, a study report in April 2021 prepared for the European Commission has noted that "AI cannot be deployed in healthcare without sufficient infrastructure and risk mitigation. Failures in the medicine industry may cause harm to individuals by, for example, failed robotic surgeries or incorrect treatment'. ${ }^{2}$

Thus, current socio-economic challenges affecting healthcare in Europe may justify the use of AI and robotics in healthcare, even if unleashing the potential of AI and robotics would require good integration with the existing and future 'technological stack' - from high-performance computing to $5 \mathrm{G}$ connectivity, nanotech and IoT, not to contribute either to address inequalities or to exacerbate them. ${ }^{3}$ Today's medical context, characterized by the pervasive impact of digital progress, requires, in fact, a reconsideration of the traditional civil law categories, in order to identify, from time to time, the necessary adaptations to preserve the protection of the health and safety of the patient/ user. $^{4}$ However, it is necessary to warn against the risk of generalizations since, just as for medical technologies, as in other fields, their degree of complexity ranges considerably depending on the specific equipment considered. The legal impact of these is thus not always such that legal adaptations are required by default. ${ }^{5}$

1. E.g. Communication from the Commission to the European Parliament, the European Council, the Council, the European Economic and Social Committee and the Committee of the Regions, Artificial Intelligence for Europe, Brussels, COM(2018) 237 final; EU Commission, Report from the Expert Group on Liability and New Technologies - New Technologies Formation, 2019, p. 3. EU Commission, Report on the Safety and Liability Implications of Artificial Intelligence, the Internet of Things and Robotics, COM(2020), 64 final.

2. A. Renda et al., Study to Support an Impact Assessment of the Regulatory Requirements for Artificial Intelligence in Europe (Final Report) (Publications Office of the European Union, 2021).

3. See the report: Z. Dolic et al., Robots in Healthcare: A Solution or a Problem? (Committee on Environment, Public Health, and Food Safety, Policy Department for Economic, Scientific and Quality of Life Policies, European Parliament, 2019) (specifically Dr Renda's contribution).

4. This finding can be extended to other private law domains. See G. Guerra, La sicurezza degli artefatti robotici in prospettiva comparatistica. Dal cambiamento tecnologico all'adattamento giuridico (il Mulino, 2018), p. 142; G. Resta, La successione nei rapporti digitali e la tutela post-mortale dei dati personali, in D. Poletti and A. Mantelero (eds), Regolare la tecnologia: il Reg. UE 2016/679 e la protezione dei dati personali. Un dialogo fra Italia e Spagna (Pisa University Press, 2018), p. 396. Big Data analytics can change legal practice, see C. Busch and A. De Franceschi, 'Granular Legal Norms: Big Data and the Personalization of Private Law', in V. Mask et al., Research Handbook in Data Science and Law (Edward Elgar, 2018), p. 408. The authors affirmed: 'the rise of Big Data could fundamentally change the design and structure of legal norms and thus the legal system itself [...] Big Data and algorithm-based regulation could lead to a shift from impersonal law based on the widespread use of typification to a more personalized law based on "granular legal norms" that are tailored to the individual addresses. As a consequence, the balance between individual fairness and legal certainty could be readjusted' (p. 409).

5. This is the position of the most influential Italian literature, see R. Leenes et al., 'Regulatory challenges of robotics: Some guidelines for addressing legal and ethical issues', 1 Law, Innovation and Technology (2017), p. 44. Contra see R. Calo, 'Robotics and the Lessons of Cyberlaw', 103 Cal. L. Rev. (2015), p. 513; A. Sandberg, 'Law-abiding Robots?', Oxford Martin Opinion (2016), www.oxfordmartin.ox.ac.uk/opinion/view/340; G. Miller, 'A Brief History of Robot Law', Atlantic (2016), www.theatlantic.com/technology/archive/2016/03/a-brief-history-of-robot-law/474156/. This debate 
For all these reasons, this article will focus on the specific case of robotic surgery as it has already become a school-case for the relevant litigation related to it. In general, with decreasing production costs and upgrading results, ${ }^{6}$ cyber surgery, ${ }^{7}$ commonly defined as the technique through which the surgeon operates remotely, has become one of the strategic areas of robotics. ${ }^{8}$ The significant reduction of human error by virtue of the precision of pre-programmed mechanical movements, the minimal invasiveness of the intervention and the possibility of operating remotely represent the distinctive features. We can distinguish at least three types of uses of the robotic system: ${ }^{9}$ to provide external support to the surgeon's action; ${ }^{10}$ to allow the intervention of a surgeon not present in the operating room; ${ }^{11}$ to manoeuvre the often cumbersome and unwieldy surgical instrumentation. ${ }^{12}$

Notwithstanding the still low level of autonomy in robotic cybersurgery, ${ }^{13}$ other features contribute in complicating the juridical analysis: the pivotal nature of a robot surgical device is embedded in the capability of carrying out a software programme so as to perform specific tasks. ${ }^{14}$ Moreover, the skill to carry out instructions is uncommitted to the degree of autonomy/independence. Actually even a remotely controlled device in use for certain surgeries as opposed to a knife, necessitates scheduling in order to smoothly react to the surgeon's commands.

is reminiscent of the historical debate about the suitable regulation of internet that was prior developed by Easterbrook and Lessig: the first one assimilated the cyberlaw to the 'law of the horse' to underline the uselessness (F. Easterbrook, 'Cyberspace and the Law of the Horse', U. Chi. Legal F. (1996), p. 207; while the second one presented the opposite perspective. Some authors assimilate the Lex Robotica to the Lex Mercatoria: E. Stradella, Approaches for Regulating Robotic Technologies: Lessons Learned and Concluding Remarks', in E. Palmerini and E. Stradella, Law and Technology: The Challenge of Regulating Technological Development (Pisa Press, 2013), p. 345.

6. Financial Times, FT Report - Innovation, 8 June 2005.

7. For the analysis of the notion of cybermedicine adopted by the US States of Montana, Nebraska, New Mexico, Oregon and Texas, see M. Hamilton-Piercy, 'Cybersurgery: Why the United States Should Embrace this Emerging Technology', 7 J. High Tech. L. (2007), p. 203.

8. See the document of the General Directorate for Internal Policies (Policy Department C: Citizens' Rights and Constitutional Affairs), Upcoming Issues of EU Law. Compilation of in-depth analysis, Workshop 24 September 2014 , p. 172. The report stated that on the basis of a recent study 'the application of advanced robotics across health care, manufacturing, and services could generate an economic impact ranging from $\$ 1.7$ trillion to 4.5 trillion per year by 2025 ... Robotic surgery (in particular minimally invasive laparoscopic surgery) is estimated as possibly reducing the number of deaths even as much as by $20 \%$ in developed countries (by providing aid to the doctor, autocorrecting movements, and by warning of potential risks), and up to $15 \%$ of all surgeries performed in countries with developed health-care systems could make use of these devices' (p. 189).

9. See J.B.M. Gagner, 'Robotics and General Surgery', 86 Surgical Clinics of North America, 2003, p. 1405. On this topic see also: R. H. Taylor et al., 'Medical Robotics and Computer-integrated Surgery', in B. Siciliano and O. Khatib (eds.), Springer Handbook of robotics, (Springer, 2008).

10. It is the most common use. The first robot of this type (Automated Endoscopic System for Optimal Positioning) was approved in 1994 by the Food and Drug Agency.

11. In this way, the surgeon can interact in videoconference with colleagues, sharing images of the body. On the cross-border nature of legal questions see B.D. Dickens, 'Robotic Surgery in Canadian law', 28 Clinical Risk (2008), p. 182.

12. E.g. the so called CyberKnife.

13. Machine learning and autonomous-machine-caused harm implicate a wider cluster of policy considerations. For a first analysis of the issues see P. Huberman, 'Tort Law, Corrective Justice and the Problem of Autonomous-Machine-Caused Harm', 34 Can. J.L. \& Juris. (2021), p. 105. See also: U. Pagallo and M. Durante, 'The Pros and Cons of Legal Automation and its Governance', 7 Eur. J. Risk Reg. (2016), p. 323.

14. The more the machine/robot is autonomous (e.g. machine learning and deep learning), the more intricate and new can be legal issues. The different level of autonomy has been discussed during the workshop dedicated to the 'roadmap on robotic autonomy', Department of Computer Sciences, University of Verona, 30-31 October 2017. Cf. P. Kazanzides et al., 'Medical Robotics - Regulatory, Ethical, and Legal Considerations for Increasing Levels of Autonomy', 2 Science Robotics (2017). 
In some cases, these robotic technologies are an extremely enhanced version of the laparoscopic ones, whereas, in other cases, they carry out operations that are unfeasible with the latter. In the last five years, there have been several steps towards the implementation of a 'robotic assistant' ${ }^{15}$ composed of teleoperating arms and arms that move autonomously based on the perception of signals from the environment, and able to react to the behaviour and (voice) commands of the main surgeon. ${ }^{16}$

Differences between various versions of the same technology, thus, give rise to a range of legal issues that are difficult to unify. Think, for example, of the relevance of data and its use, where system interoperability, connectivity and sharing with other systems (the internet of things) may not depend on the manufacturer's original program and interfere with the latter's business. ${ }^{17}$

From these initial observations emerges the need for an appropriate regulatory framework capable of regulating the use of data and the consequences that depend on such use and that allow artificial intelligence to function. This is an objective underlying the most recent European data policy. ${ }^{18}$

Anyway, in general terms, the field of robotic surgery shows the impact on liability rules and the need for the transformation of the roles of doctors and patients in an age of ubiquitous information. ${ }^{19}$ For instance, European institutions are taking into account whether professional liability might bring about suitable incentives to appropriately train robot-surgeons, as inappropriate surgery may lead to death in patients, so dictating ex-ante prerequisites on robot-surgeons may prove more suitable. $^{20}$

To sum up, this article first considers and describes the status quo of the EU recent regulatory directions of AI and robotics specifically dedicated to managing safety and liability profiles to test if they provide an answer to all the practical tort law issues already identifiable through a consistent case law that has arisen in the US jurisdiction where robotic surgery was approved earlier and taken to market. From a methodological point of view, the most traditional comparative approach will be integrated with elements - such as empirical data and context analysis - to follow the path of the most contemporary comparative scholarship. ${ }^{21}$

15. The reference is to the project (H2020) SARAS, Smart Autonomous Robotic Assistant Surgeon, conducted by the Department of Computer Sciences, University of Verona (https://saras-project.eu/).

16. The implemented level of autonomy is from level 0 to level 1 . This was clearly described by P. Fiorini, Le tecnologie e le applicazioni della robotica autonoma: dove si nascondono gli aspetti legali?, during the webinar Profili giuridici dell'utilizzo della robotica e dell'intelligenza artificiale in medicina, June 12, 2020, Department of Computer Science, Verona University, Verona, Italy.

17. Main features of digital technologies are reported by Report on the Safety and Liability Implications of Artificial Intelligence, the Internet of Things and Robotics, COM(2020) 64 final.

18. See section 2 .

19. JRC Science for Policy Report, AI Watch: Artificial Intelligence in Medicine and Health Care: Applications, Availability, and Societal Impact (Publications Office of the European Union, 2020).

20. R. Leenes et al., 1 Law, Innovation and Technology (2017), p. 44.

21. For a preliminary references see: M. Siems, 'The Power of Comparative Law: What Type of Units Can Comparative Law Compare?', 67 American Journal of Comparative Law (2019), p. 861; H. Spamann, 'Empirical Comparative Law', 11 Annual Review of Law and Social Science (2015), p. 131; U. Kischel, Comparative Law (Oxford University Press, 2019); D. Nelken, 'Comparative Legal Research and Legal Culture: Facts, Approaches, and Values', 12 Annual Review of Law and Social Science (2016), p. 1; A. Riles, 'Comparative Law and Socio-Legal Studies', in M. Reimann and R. Zimmermann, The Oxford Handbook of Comparative Law, (2nd ed., Oxford University Press, 2019), p. 773; M. Siems, New Directions in Comparative Law, in M. Reimann and R. Zimmermann (eds.), The Oxford Handbook of Comparative Law, (2nd ed., Oxford University Press, 2019). 
The essay is structured in three parts: section 2 describes the most recent European regulatory framework on safety and liability of AI applications and, for completeness, pays particular attention to illustrating the coordination between new AI regulatory measures and the existing regulatory framework for medical products/applications; section 3 draws on the experience provided by the American litigation concerning damages from robotic surgery to identify the main emerging profiles; ${ }^{22}$ section 4 adopts the European perspective to understand whether the current European regulatory framework could provide a satisfactory response to the occurrence of similar problems and thus assess the suitability of the policy guidelines undertaken. It identifies the specific 'lessons'. This is followed by some concluding remarks (section 5).

\section{General remarks on the EU framework for Al...}

Although in the economy of these pages we must limit ourselves to a few framework hints, the issue in question should certainly be read in the light of two 'regulatory coordinates': the Artificial Intelligence Act with which the European Commission has put forward the Proposal for a Regulation establishing harmonized rules on artificial intelligence and amending some EU legislative acts; and, for a comprehensive vision, in light of the way the AI Act will interplay with the existing legislative framework, especially with the one concerning medical products (see section 2.A). ${ }^{23}$

To start with, the European AI framework is an extensive intervention with which Europe implements the political objectives expressed with a considerable amount of work in recent years to create a European approach on the human and ethical implications of AI. ${ }^{24}$ In fact, to tackle social concerns and doubts about legal uncertainty for businesses that are marketing their products involving AI, European authorities have intensively worked to create an 'trustworthy ecosystem' ${ }^{25}$ suitable for the 'algorithm society'.26 an environment that aims at protecting the conformity to the European law already

22. The Da Vinci robot is produced by the American Intuitive Surgical Inc. Cf. M. Goldberg, 'The Robotic Arm Went Crazy: The Problem of Establishing Liability in a Monopolized Field', 38 Rutgers Computer \& Tech L. J. (2012), p. 225. For a deeper analysis on the US robotic surgery litigation see G. Guerra, 'Profili di responsabilità del produttore di robot chirurgico nell'ordinamento americano', 2 Responsabilità medica. Diritto e pratica clinica (2020), p. 215.

23. European Commission, Proposal for a Regulation of the European Parliament and of the Council Laying Down Harmonised Rules on Artificial Intelligence (Artificial Intelligence Act) and Amending Certain Union Legislative Acts, COM(2021) 206 final 2021/0106 (COD). As there are still a very limited number of comments about the complex Act, the paper is in debt of a number of very recent conventions and seminars finalized to present early comments and explanations of the Act: e.g. Europe rulez AI. Commenting on the European Proposal for an AI regulation, June 15, 2021, organized by EURA, Sant'Anna University, Italy; or the Münster Colloquia on EU Law and the Digital Economy, Smart Products, 10/11 June 2021, organized by Westfalische universitat-Universität Münster.

24. A comprehensive vision of the rich policy and regulatory framework is proposed by the Proposal for a Regulation of the European Parliament and of the Council Laying Down Harmonized Rules on Artificial Intelligence (Artificial Intelligence Act) and Amending Certain Union Legislative Acts COM(2021) 206 final 2021/0106 (COD).

25. With reference to the context of self-driving vehicles, algorithmic decision might acquired a crucial importance because they implied ethical choices. A recent experiment of the Massachusetts Institute Technology showed how the acceptability of the algorithmic choices vary depending on the geopolitical context considered could translate, in the future, into the need for the car manufacturer to prepare algorithmic solutions that differ according to the market in which the product is marketed. See E. Awad et al., 'The Moral Machine Experiment', 563 Nature (2018), p. 59. Following the MIT findings, automotive industries might need to produce different car software depending on the market.

26. See M. Schuilenburg and R. Peeters, The Algorithmic Society: Technology, Power, and Knowledge (Routledge, 2021). 
in force, protecting fundamental and consumers' rights, ${ }^{27}$ through an anthropocentric approach. $^{28}$

We'll now recap briefly before concentrating on the concerns of the AI Act which are additionally affecting/influencing the topic at hand in this article (see in particular section 2.A). In recent times, European policy initiatives pursed the goals in AI field working on several fronts. The specific matters of liability have always been a key issue to face. Back in 2016, the Committee on Legal Affairs of the European Parliament (EP) published a pioneering initiative: the Resolution with recommendations to the Commission on Civil Law Rules on Robotics. The EP proposed rules that were intended to bring a common EU solution to the legal challenges posed by, amongst others, smart autonomous robots. ${ }^{29}$ If the safety risks materialize, the lack of clear requirements and the characteristics of AI technologies mentioned above make it difficult to trace back potentially problematic decisions made with the involvement of AI systems. This in turn may make it difficult for persons having suffered harm to obtain compensation under the current EU and national liability legislation $^{30}$

Anyway, this first piece of EU policy was highly criticized. ${ }^{31}$ It was, in fact, followed by directions much more focused on specific characteristics of AI applications (such as opacity). ${ }^{32}$ This is

27. Lastly, this point was expressed by the EU Commission, Communication on Building Trust in Human-Centric AI, $\operatorname{COM}(2019)$ 168, and by the documents of the EU Commission, High-Level Expert Group on Artificial Intelligence (AI HLEG). For more details see the website of the European Union Agency for Fundamental Rights: https://fra. europa.eu/en/themes/artificial-intelligence-and-big-data.

28. EU Commission, White Paper On Artificial Intelligence - A European Approach to Excellence and Trust, COM(2020) 65 final.

29. The document arguments that robots should have some form of legal personality gain credence. These kind of arguments are typically framed in instrumental terms, with comparisons to juridical persons such as corporations see: S. Chesterman, 'Artificial Intelligence and the Limits of Legal Personality', 69 International \& Comparative Law Quarterly (2020), p. 819; T.G. García-Micó, 'Electronic Personhood: A Tertium Genus for Smart Autonomous Surgical Robots?', in M. Ebers and M. Cantero Gamito (eds), Algorithmic Governance and Governance of Algorithms: Data Science, Machine Intelligence, and Law, vol 1. (Springer, 2021).

30. White Paper on Artificial Intelligence - A European Approach to Excellence and Trust, COM(2020) 65 final.

31. Primarily because it proposed to attribute legal personhood to robots, but this is problematic for several reasons: see the Report of COMEST on Roboticsethics of UNESCO of 14 September 2017, Paragraph 201that explains that 'it is highly counterintuitive to call them "persons" as long as they do not possess some additional qualities typically associated with human persons, such as freedom of will, intentionality, self-consciousness, moral agency or a sense of personal identity'; World Commission on the Ethics of Scientific Knowledge and Technology. Report of COMEST on Robotics Ethics (2017), http://unesdoc.unesco.org/images/0025/002539/253952E.pdf. Moreover, European Economic and Social Committee on AI of 31 May 2017 considers 'the comparison with the limited liability of companies is misplaced, because in that case a natural person is always ultimately responsible' (para. 3.33).

32. EU Commission, Report from the Expert Group on Liability and New Technologies - New Technologies Formation, 2019, p. 32. Besides all the technical disruptive characteristics mentioned by the Expert Group, it described 'complexity' as 'modern-day hardware can be a composite of multiple parts whose interaction requires a high degree of technical sophistication. Combining it with an increasing percentage of digital components, including AI, makes such technology even more complex and shifts it far away from the archetypes of potentially harmful sources on which the existing rules of liability are based. Where, for example, an AV interacts with other AVs, a connected road infrastructure and various cloud services, it may be increasingly difficult to find out where a problem has its source and what ultimately caused an accident. The plurality of actors in digital ecosystems makes it increasingly difficult to find out who might be liable for the damage caused. Another dimension of this complexity is the internal complexity of the algorithms involved.' Consider also biases that algorithms may produce through the input data, the testing of the algorithm and the decision model. Any transparency requirement for algorithms should result in explanations of these biases that are both understandable for the prospective recipients, and technically feasible for producers. Before asking how much transparency the law should require from algorithms, we should therefore consider if the explanation that programmers could offer 
because with regard to emerging technologies, and in particular AI also incorporated in robots, the European legislator has revealed, first of all, the difficulties from the point of view of definition and classification: the distinction between products and services is blurring with the increasing overlap of the respective disciplines.

For all the problematic issues derived from this and other structural features, the AI Act of the 2021 lays down (a) the harmonized rules for the placing on the market other than into service and the use of artificial intelligence systems; (b) harmonized transparency rules for AI system and rules on market monitoring and surveillance (article 1 of the AI Act). On the whole, the overall aim of the AI Act is 'horizontal but not comprehensive': ${ }^{33}$ it implies that it is eager to tackle certain specific features of AI that can make application and enforcement of the operative rules in place more challenging, exposing more risks to (a) safety, and (b) fundamental rights.

The acknowledgment that a solid framework of EU legislation is already operative at a EU and national level suggests the urgency to incorporate the new specific prerequisites of the AI Act with the existing Regulation. By virtue of the fact that the AI Act complies with the product safety logic and not the services one, a deep reflection with regard to the safety legislation will be necessary in order to respond to the robotic medicine, and more particularly with accuracy in relation to: (i) the new differentiation of high-risk AI systems and (ii) the revision of horizontal and vertical European legislation on safety at the aim to integrate specific requirement.

As the AI goal is to discipline AI cases proportionally to their level of risk, and not all the AI applications, ${ }^{34}$ it is first pivotal to understand which are the high-risk AI systems. The Proposal enforced a risk-based approach (article 7 AI Act) based on which it distinguished AI applications with minimal or no risk; applications with high risk and/or transparency risks; and unbearable hazards. Pertaining to high-risk AI applications, the Act introduces several distinctions in Title III, chapter 1 and Annexes II and III and the reason for this articulated choice was generated by legislative technicalities of the EU law: current (vertical) safety regulation is based on two distinct categories, one belongs to 'new approach' (e.g. medical devices and machinery) that authorizes automatic complementarity without any additional implementing step and requirements; the other one is part of the 'old approach' and is highly technical, expressing already-specific safety requirements, and for this reason it doesn't permit automatic complementarity, thus it needs to be amended first of all (this second type is particularly used in mobility sector). ${ }^{35}$

This will be a crucial definition for our purposes in order to come back at the end of the following legal reasoning and confirm the important consideration of the nature of the examined robotic surgery (see section 4).

As regards the second point (ii), it has to be remarked that some steps further have already taken place, for example underlining the need to overcome the said distinction between product and service and from the combination of the product with that of the 'system'. ${ }^{36}$ The Report of the

is useful in specific legal contexts. For these arguments see M.C. Buiten, 'Towards Intelligent Regulation for Artificial Intelligence' (Symposium on Regulating the Risk of Disruptive Technology), 10 Eur. J. Risk Reg. (2019), p. 41.

33. In this terms the AI Act was described by Tatjana Evas, a Policy Analyst in the European Parliamentary Research Service and one of the drafter of the AI Act, during the seminar Europe rulez AI. Commenting on the European Proposal for an AI regulation, June 15, 2021, organized by EURA.

34. This was clearly stated by Tatjana Evas, ibid.

35. Ibid.

36. Report on the Safety and Liability Implications of Artificial Intelligence, the Internet of Things and Robotics, $\operatorname{COM}(2020) 64$ final, p. 10. For an in-depth analysis see G. Guerra, La sicurezza degli artefatti robotici in prospettiva comparatistica. Dal cambiamento tecnologico all'adattamento giuridico. 
European Commission on the safety and liability implications of artificial intelligence, the internet of things and robotics of 19 February 2020, for example, highlights the impact of this issue on the classical categories of civil law. ${ }^{37}$ For example, consider the evolution of the concept of defectiveness, which clearly exemplifies the impact of complexity on traditional concepts, and how research approaches should hopefully evolve in order to capture new features that warrant legal change or adaptation. The soft law framework has outlined that some types of risks associated with the use of automated processes and advanced artificial intelligence systems are regarded as failures whose origin is very difficult to prove.

With a specially established study group, the Expert Group on Liability and New Technologies (New Technologies Formation), the European Commission has indicated that the current applicable regulations could prove inadequate to repair the damage caused by algorithmic operations. ${ }^{38}$ The idea is to regulate algorithms by using them as a regulatory tool: in fact, non-regulatory tools are included in order to consider technology as a regulatory target or as a means of regulation (regulatory tool). ${ }^{39}$

Thus the algorithm itself becomes a mean to manage the speed and predictive power that determine the operation of many products. It is, therefore, central to the issue of the reliability of the choice options they generate. Algorithms are based on information. Information are based on data. Data is at the heart of the EU's digital transformation that is influencing all aspects of society and the economy. It is necessary for the development of artificial intelligence, which is one of the EU's priorities. This implies, also for the specific legal aspects considered here, the need to adopt a broader regulatory perspective, able to coordinate not only the so-called horizontal regulation of product safety and liability with the sectoral regulation of medical products, but also with the constantly evolving framework of the European Strategy for Data. ${ }^{40}$

The civil law issues that institutions need to analyse in order to set up an effective regulatory framework are many.

37. Report on the Safety and Liability Implications of Artificial Intelligence, the Internet of Things and Robotics, $\operatorname{COM}(2020) 64$ final.

38. EU Commission, Report from the Expert Group on Liability and New Technologies - New Technologies Formation, 2019, p. 3. The Expert Group observed that: 'the liability regimes in force in the Member States ensure at least basic protection of victims whose damage is caused by the operation of such new technologies. However, the specific characteristics of these technologies and their applications - including, modification through updates or self-learning during operation, limited predictability, and vulnerability to cybersecurity threats - may make it more difficult to offer these victims a claim for compensation in all cases where this seems justified. It may also be the case that the allocation of liability is unfair or inefficient. To rectify this, certain adjustments need to be made to EU and national liability regimes.'

39. This distinction was introduced by R. Brownsword and K. Yeung, Regulating Technologies: Legal Futures, Regulatory Frames and Technological Fixes (Hart Publishing, 2008), p. 3. See also R. Brownsword, Law, Technology and Society: Re-imaging the Regulatory Environment (House Book, Routledge, 2019). The impact of automation on different fields give us several examples: e.g. in contract law the problem of the pre-determination of the algorithmic contracts.

40. The Commission presented a European strategy for data in February 2020. The strategy and the White Paper on artificial intelligence are the first pillars of the Commission's digital strategy. The data strategy and the White Paper on Artificial Intelligence are the first pillars of the new digital strategy of the Commission. They all focus on the need to put people first in developing technology, as well as on the need to defend and promote European values and rights in how we design, make and deploy technology in the economy. The Commission has proposed a Regulation on European data governance as part of its data strategy. This new Regulation will play a vital role in ensuring the EU's leadership in the global data economy. Proposal for a Regulation of the European Parliament and of the Council on European Data Governance (Data Governance Act), $\operatorname{COM(2020)} 767$ final; White Paper on Artificial Intelligence - A European Approach to Excellence and Trust $\mathrm{COM}(2020) 65$ final. 
Traditionally, algorithms have been considered as mere product-instruments. More current legal research has, in fact, begun to question whether the notion of defect can be applied to the algorithm per se. ${ }^{41}$ In practice, the question is whether it is appropriate to identify as the object of imputation of the malfunction the product that incorporates the AI in its physicality, i.e. the algorithms that generate the decision from which the material action of the product derives. ${ }^{42}$

First, it should be noted that the drafters of the directive potentially applicable in this case, i.e., Directive $85 / 374 /$ EEC, could not contemplate this issue. ${ }^{43}$ The few references are contradictory; however. considering the purpose of the directive, the answer seems to be affirmative (at least for the time being). ${ }^{44}$ Under the Product Liability Directive 85/374/CEE, a manufacturer is liable for damage caused by a defective product. However, in the case of an AI-based system such as autonomous cars, it may be difficult to prove that there is a defect in the product, the damage that has occurred and the causal link between the two. In addition, there is some uncertainty about how and to what extent the Product Liability Directive applies in the case of certain types of defects, for example if these resulted from weaknesses in the cybersecurity of the product.

\section{I. (continued) ... and specific remarks on the complementary interplay between the Al Act and the Medical Device Regulation}

As anticipated in section 2, in order to complete the regulatory 'patchwork', it is necessary to understand how the new measures contained in the AI Act will be integrated into the EU Regulation for Medical Devices.

First of all, there isn't already a specific EU regulation for the class of medical robots. Generally speaking, surgical robots, by being labelled medical devices, are treated no different than other medical devices used in surgical operations, such as scissors and scalpels.

Especially in the medical devices sphere, the use of Artificial Intelligence is escalating conspicuously. Nevertheless, the current legal framework raises certain reservations pertaining to the relation between AI and medical devices. The Medical Device Directive solely regulates the function, design and construction requirements of medical devices and not the risks involved in robot surgery, which are determined by a complex human-machine interplay. ${ }^{45}$

To this extent, given the diverse application and interpretation of AI as medical devices, it is still uncertain whether a software using AI may or may not be deemed as falling under the scope of the Medical Device Regulation and be classified as such.

41. J.S. Borghetti, 'How can Artificial Intelligence be Defective?', in S. Lohsse et al., Liability for Artificial Intelligence and the Internet of Things, Münster Colloquia on EU Law and the Digital Economy IV (Hart Publishing, Nomos, 2019).

42. Cf. K. Chagal-Feferkorn, 'The Reasonable Algorithm', 1 Journal of Law, Technology and Policy (2018), p. 113.

43. Council Directive 85/374/EEC of 25 July 1985 on the approximation of the laws, regulations and administrative provisions of the Member States concerning liability for defective products, [1985] OJ L 210.

44. See also J.S. Borghetti, 'Is Defectiveness an Appropriate Notion to Deal with Damage Associated with the IoT or Artificial Intelligence?', speech at the Munster Colloquia on EU Law and Digital Economy.

45. Directive 93/42/EEC and subsequent modifications, lastly by Regulation (EU) 2017/745 of the European Parliament and of the Council of 5 April 2017 on medical devices, amending Directive 2001/83/EC, Regulation (EC) No 178/2002 and Regulation (EC) No 1223/2009 and repealing Council Directives 90/385/EEC and 93/42/EEC, OJ L 117, p. 1). Regulation (EU) 2020/561 of the European Parliament and of the Council of 23 April 2020 amending Regulation (EU) $2017 / 745$ on medical devices, as regards the dates of application of certain of its provisions. According to article 120(2) of Regulation (EU) 2017/475 on Medical Devices (the MDR), certificates issued in accordance with Directive 93/42/EEC will remain valid until 27 May 2024 at the latest. 
In any case, as previously anticipated (see section 1), the range of risks in typology and extent of hazards highly depend on the category of robotic applications and on the sector-specific Regulation applicable. More specifically the robotic surgery is not characterized yet by a high degree of complexity, namely machine learning, thus it is worth thinking in terms of teleoperation system (see infra).

Consequently, in the future perspective of remarkable developments in medical robotics, and based on the general remarks just expressed about the legislative nature and logic of safety regulation (see section 2) we have to consider the Medical Device Regulation as part of the "new regulatory approach': as a matter of legislative technique, one of the drafters of the Proposal of AI Act, Professor Evas, clearly explained ${ }^{46}$ that the regulations in question will automatically integrate the AI requirements, without amendments. This automatic regulatory alignment could happened in case the medical robot will raise the level of complexity or will present crucial issues of transparency in the way it will operate as foreseen for high-risk AI applications.

Anyway, for the ongoing stage of technological development there is the need to ensure that the robot can work within a safe and secure ecosystem. Trustworthy patch management might prove paramount in surmounting weaknesses that might appear - this would always guarantee the abilities of the device. If no patch is accessible and a familiar or unfamiliar vulnerability is in place that can be harnessed, then we would need more than merely patch management.

However, surgical robots lack clear parameters that outline the meanings of safety, accuracy and specific procedures to assess them, as opposed to their industrial counterparts/homologues, for which criteria such as ISO 9283 are in place. A parallel can be identified in other upcoming technologies such as automatically piloted vehicles. Standards such as IEC 60601 furnish guidelines/ directives to outline the extents of autonomy of medical gear, yet its purpose is targeted at evaluating the risk of a device rather than manage it. ${ }^{47}$ For robotic surgery on living patients, Common Criteria security certification should be a requirement, similar to ISO/IEC 15408 for the automotive industry.

One could argue that robotic-assisted surgery equipment such as the da Vinci should be truly considered a manipulator instead (ISO 8873). Currently many assume that there is consent for robotic-assisted surgery that entails human remote-control. Nevertheless this is not completely accurate. In the US and likewise in Europe and elsewhere, the da Vinci surgical robot is allowed for use on humans, yet that robot is entirely commanded by a highly skilled and specially trained surgeon (see section 3).

On the whole, considering medical robots through the integrated perspectives of AI Act and Medical Product Regulation one can remark that, even in the case of comparing robotic surgery to teleoperation systems without classifying them as high-risk products, they could benefit from the general remarks expressed with the AI Act. According to the Proposal of a Regulation harmonizing rules on Artificial Intelligence, an AI system used as a medical device shall be classified as high risk, and shall undergo scrutiny by a Notified Body (COM, 2021, Art. 6). Moreover, the device shall comply with all the requirements already established by the Medical Device Regulation, but also those laid down in Chapter II of the Proposal for an AI Regulation (COM,

46. I am referring to Prof. Tatjana Evas's speech, see n. 33. As she described, the opposite approach is the old approach, based on which certain types of regulations (e.g. regulation in transportation field) need to be amended in case a new regulation interferes with it.

47. S. O'Sullivan et al., 'Legal, Regulatory, and Ethical Frameworks for Development of Standards in Artificial Intelligence (AI) and Autonomous Robotic Surgery', 15 Int J Med Robotics Comput. Assist. Surg. (2019), p. 196. 
2021, Arts. 8, 43(3). ${ }^{48}$ In this perspective, the provider that will produce robotic medical devices classified as high-risk applications will have to implement some additional requirements applying a pre-market conformity assessment and certify compliance with them along with the life circle of product.

A Special Committee on Artificial Intelligence in a Digital Age (AIDA) established by the European Parliament has already directed all its efforts in filling current regulatory gaps to develop a European framework on Artificial Intelligence, which was published by AIDA in a Working Paper on AI and Health. ${ }^{49}$ In line with the AI Act, AIDA identifies the need to harmonize the governing rules across the EU, integrating ethical rules from the very first stages of the development and design of AI devices, and the adequate protection and safeguards for consumers. Especially concerning this last point, meaningful human control, safety, validation of software applied to health and trustworthiness of algorithm-powered diagnoses shall be ensured (AIDA, 2021).

Given the significant hazards which can be coupled with devices of this nature, it is mandatory to guarantee that risks assessments and safety requirements can contemplate any new activity acquired and conducted by the AI.

Concluding this section, it is important to consider that if the AI Act will be adopted, manufacturers of AI system as medical devices shall comply both with MDR requirements and with those listed in the Artificial Intelligence.

\section{The US instructive experience}

An examination of the US case study history on robotic surgery has a range of purposes: first of all, it aims to identify if, and if so which, challenging issues emerged in the advanced US area in robotic surgery; second, it aims to understand whether the identified issues are novel challenges in tort law or whether they were already dealt with in the past, for example in laparoscopy damages litigation, or they somehow aggravate or diversify existing problems (sections 3.A and 3.B). Lastly, it is expected - without any ambitions to foresee the future or a precognitive purpose - to supply preliminary insights about how to cope with similar issues in Europe (section 4) keeping 'responsible' innovation and the trust of providers, patients, consumers, and investors. ${ }^{50}$

48. These requirements include risk management; human oversight; transparency and provision of information to users; record-keeping. Manufacturers shall also ensure that the requirements of Chapter III of the AI Regulatory Proposal are complied with (COM 2021, Article 16). These closely resemble the requirements under the Medical Device Regulation and include: Appointment of Authorized Representative; Quality Management System; Affixing of CE marking on the AI system.

49. EU Parliament (Special Committee on Artificial Intelligence in a Digital Age), AIDA Working Paper on Artificial Intelligence and Health, 2021. See www.europarl.europa.eu/committees/en/aida/home/highlights. AI is considered to refer to computer programs having the capacity to perform operations analogous to learning and decision-making in humans (COM 2021, Article 3). AI technologies may potentially optimize the performances of devices in a continuous manner, autonomously, evolving in real time and adapting to its data input.

50. On the issue of damages for robotic surgery see the principal cases: Mendoza v. Intuitive Surgical, Inc., No. 18-CV-06414-LHK, 2020 WL 3078178 (N.D. Cal. June 10, 2020); Kucharczyk v. Intuitive Surgical, Inc., No. 45052-6-II, 2015 (July 07, 2015); Vanderford v. Intuitive Surgical, Inc., 4:2013cv02993, (June 28, 2013); Tremblay v. Intuitive Surgical, Inc., Case No. 12-cv-00231-JSW (June 6, 2013); Chronister v. Intuitive Surgical, Inc., 6:12-cv-01184-GAP-DAB, (June 16, 2013); Kucharczyk v. Intuitive Surgical, Inc., No. CV12-03760 JSW (November 8, 2012); O'Brien v. Surgical, Inc., 1:10-cv-03005 (July 25, 2011); Dulski et al v. Intuitive Surgical, Inc. et al, 1:2010cv00234 (February 9, 2011); O’Brien v. Intuitive Surgical, Inc. 1:2010cv03005 (May 17, 2010); 
The specific application 'protagonist' of the case law in question is, as previously mentioned, the teleoperated robot 'Da Vinci': a system consisting of mechanical arms controlled remotely by the professional, who remains, therefore, away from the operating table, carrying out his work through a console that provides a three-dimensional view with a realistic depth of the intervention field. The surgical instruments necessary for the operation to be performed are attached to the mechanical arms. The specialist utilizes two hand-pieces, placed under the display, to control all the robotic instruments. The system is able to perfectly translate the movements of the surgeon's hand, wrist and fingers into simultaneous and precise movements of the instruments, 'filtering' the natural physiological tremor of man.

Through the database Manufacturer and User Facility Device Experience (MAUDE) of the Food and Drug Administration Agency (FDA), which collects the 'reports' for adverse events of medical devices, reported by various subjects both on a voluntary and mandatory basis, ${ }^{51}$ shows that since 2000 , the year of authorization, the number of cases of malfunction, physical damage, and deaths caused by the same exceeds tens of thousands. However, according to many experts, this number would be much lower than the real one, as the latter is difficult to identify: many side effects, such as intestinal and bladder injuries, perforated or cut ureters, perforation of organs, or burns of organs have, in fact, occurred long after the intervention, and the etiological reconstruction is doubtful.

There were so many complaints that in 2013 the FDA itself launched a surveillance procedure to verify the causes. ${ }^{52}$

Litigation on the matter also grew unabated, and was mostly settled out of court. ${ }^{53}$

The material facts of the main American cases analysed are similar: due to a malfunction, the Da Vinci freezes during surgery and the surgeon is forced to continue with traditional laparoscopic techniques. Because of this, the patient manifests various types of damage (burns, pain, dysfunction) long after the surgery.

Most cases have been concluded through out-of-court settlements. However, currently the pending litigation related to the Da Vinci is still of significant proportions. It may seem strange that no real class actions have been proposed. ${ }^{54}$ For reasons of expediency, the injured parties have preferred to resort to another mechanism used in the United States, the so-called Multi-District Litigation (MDL) on the basis of which the procedure in a federal court is established to transfer many pending state judgments and reduce the risk of conflicting judgments on the same issue, thus making the process faster.

The major decisions in this area are briefly as follows. ${ }^{55}$ One of the first cases dates back to 2005 , when Mr. Roland Mraceck underwent robotic prostate removal surgery at Bryn Mawr Hospital

Bresnahan v. Intuitive Surgical, Inc. and Chip Bowman, 1:09-cv-06272 (October 25, 2010); Mracek v. Bryn Mawr hospital et al. No. 2:08-cv-00296 (March 11, 2009).

51. MAUDE database is available at: www.accessdata.fda.gov/scripts/cdrh/cfdocs/cfmaude/search.cfm. Between 2000 and 2013 (the year of FDA surveillance procedure), one can count more than 10,000 cases, including more than 8,000 malfunctions; more than 1,400 bodily injury claims and more than 140 fatalities. These cases are only a small percentage of the cases than happened in that period. Experts observed that the number of reports can be most likely underrepresented.

52. Cf. www.advisory.com/Daily-Briefing/2013/04/12/FDA-launches-investigation-into-da-Vinci-complaints.

53. This information is also available on the case Zarick v. Intuitive Surgical Inc. (Superior Court of California, Santa Clara County, case number 1-12-CV-237723, decided on April 7, 2016). For more data see also: www.law360.com/articles/ 782201/intuitive-surgical-owes-300m-for-bad-robot-jury-told.

54. See http://surgicalwatch.com/davinci-robot/lawsuit/. In the meantime, surgery litigation also increased, to the point that in 2015 the first class action was fulfilled in Missouri.

55. In 2018 the US Securities and Exchange Commission made it known that Intuitive Surgical had set aside \$17.4 million to settle outstanding judgments as of 31 March 2018. 
following the diagnosis of cancer. ${ }^{56}$ During the prostatectomy operation, the robot blocked, the display repeatedly showed 'error' and the surgeon continued the operation using the traditional laparoscopic technique.

A week after the operation, and probably due to the interruption of the robot's operation, the patient showed several pathologies (haematuria, erectile dysfunction and severe pain) and decided to file a claim against the hospital and the Da Vinci manufacturer. The patient's family sued, claiming that the defendants were responsible for negligence and malfunction of the device. However, none of these claims was upheld, as the court considered that there was no proof of a causal link between the damage suffered by the patient and the alleged malfunction of the robot (not even the plaintiff's urologist offered his opinion on the existence of causality between surgery and subsequent pathologies).

On appeal, ${ }^{57}$ the US Third Circuit Court of Appeals also excluded the manufacturer's liability on the same grounds. The burden of proof of the defectiveness is one of the most problematic profiles in this matter and will be the subject of specific discussion below.

The plaintiff encountered similar difficulties in the case of Daniel J. O'Brien versus Intuitive Surgical Inc. ${ }^{58}$ The patient, after having undergone a pancreatectomy, complained of damage resulting, according to the plaintiff, from a design defect and the consequent malfunction of the surgical robot, which had been replaced by traditional techniques. Of the actions taken, for strict liability and for misrepresentation, the only one potentially available - according to Judge Feinerman's opinion - was to affirm liability for the defect of the robot. However, the court observed that the robot is produced with the aim of 'supporting' the action of the surgeon, so that in case of failure or malfunction of the same, the surgeon is required to continue the operation with the ordinary instrumentation. In other words, for the Illinois District Court, there was no allegation of proximate causation, which is an essential element in a strict product liability action. According to the court's reasoning, two facts - if attached and proven by the plaintiff - would have demonstrated the existence of causation between fact and damage: the malfunction of the device, as a direct cause of the physical damage to the patient; and the delay in performing the alternative laparoscopic operation.

This same guidance from the court appears to have been incorporated by the plaintiff in the 2012 case of Silvestrini v. University Healthcare System, L.C., d/b/a Tulane University Hospital and Clinic ('TUHC') and Intuitive Surgical, Inc. ${ }^{59}$ The plaintiff, who was admitted to TUHC, underwent thyroidectomy using robotic assist instrumentation after being informed that the latter was less invasive than traditional techniques. Again, the malfunction of the robot that occurred during the procedure was not resolved by the surgeon or other medical personnel. With the consent of the anesthetized plaintiff's family members, the surgery continued with traditional instrumentation. This change involved a long surgical cut on the patient's neck, and subsequent plastic surgery to remedy it, as well as further interventions, since the surgeon was not able to remove the entire thyroid anyway. The plaintiff complained that the medical staff were 'totally deficient, inadequate and inept' in the use of the robot. In fact, the staff had not received adequate training from the

56. This is not the first case. News-reported cases back in 2002 concluded extrajudicially.

57. Mracek v. Bryn Mawr Hosp. and Intuitive Surgical Inc., 363 F. App'x 925, 926 (January 28, 2010).

58. Daniel J. O'Brien vs. Intuitive Surgical Inc., see n. 50.

59. Silvestrini v. University Healthcare System, L.C., d/b/a Tulane University Hospital and Clinic ('TUHC') e Intuitive Surgical, Inc., No. 11-2704 (E.D. La. Feb. 6, 2012). 
manufacturer, in violation of the terms of the supply agreement between the manufacturer, the robot supplier and the hospital.

Also in this case ${ }^{60}$ however, the claims against the hospital and the manufacturer were rejected for lack of jurisdiction of the court. ${ }^{61}$

In Taylor v. Intuitive Surgical Inc of March 25, 2013, the Superior Court of the State of Washington turned the litigation on its head by holding the manufacturer liable for breach of its duty to warn and train medical personnel. ${ }^{62}$ In spite of the Da Vinci manufacturer's warnings about the robot's unsuitability for use on obese patients, the surgeon decided to use it on such a patient who had already undergone multiple surgeries. As in other cases, the robot was replaced due to malfunction during surgery. During and after his 2008 prosthodontic surgery, Mr. Taylor complained of physical injuries. The plaintiff first, and then his heirs, brought suit against the manufacturer alleging violations of the Washington Product Liability Act for failure to instruct and train personnel who were unable to remedy the problem. Accepting, in part, the demands of the plaintiff, the court did not grant, unlike what happened in the past, summary judgment to the defendant. ${ }^{63}$

For the Washington court there was no duty to instruct in common law. ${ }^{64}$ It follows from the more general duty to maintain reasonable commercial conduct when a relationship is established between the parties involved (the marketing duties). In the area of product liability, the Washington Products Liability Act ('WPA') ${ }^{65}$ requires the manufacturing company to provide warnings and instructions on the use of the product, without specifying who the recipient is. According to the Act, instructions, warnings and training must be considered inadequate if, at the time of production, the likelihood that the product could cause harm to the end user, and the severity of that harm, were sufficient to require the manufacturer to provide information that the consumer would consider adequate.

The matter, therefore, is governed by this express provision of the WPA, which implicitly 'preempted' the application of the common law rule. ${ }^{66}$

60. The plaintiff based the liability action by the hospital (TUHC) on the basis of a multiple omissions: the lack of maintenance of the robot; the lack of information and representation to the plaintiff of the possible failure, or malfunction of the robot; the use of the surgical robot without the availability of technical personnel capable of correcting the cause of malfunction; the lack of guidelines, or protocol relating to the procedures for the use of the robot; the inadequate preparation of the surgeon in charge of the operation and the staff to intervene promptly and resolve the issue.

61. Following Louisiana State Law, the plaintiff should suit the medical review panel before experiencing the legal action. See Silvestrini v. University Healthcare System, L.C., d/b/a Tulane University Hospital and Clinic ('TUHC') e Intuitive Surgical, Inc., see n 60.

62. Taylor v. Intuitive Surgical Inc No. 92210-1 (Wash. March 25, 2013). Recently, another case where the summary judgment was not granted to the claimant (Intuitive Surgical) was concluded out of the court resolution. See Zarick v. Intuitive Surgical Inc, 1-12-CV-2377232016 (April 21, 2016).

63. Summary judgment is the most meaningful pretrial motion stated by the Rule 56 of Federal Rules of Civil Procedure. Specifically, Article 56(a) stated that the summary judgment is stated when 'the movant shows that there is no genuine dispute as to any material fact and the movant is entitled to judgment as a matter of law'. More details are available from J.H. Friedenthal et al., Civil Procedure (4th ed., Hornbook, 2005); and C.E. Charles and C.U. Samenow, 'The Summary Judgment', 38 Yale L.J. (1928-1929), p. 423.

64. In this context the expression 'common law' is used in opposition to 'unwritten' rules to the statutes. Regarding the plurality of meanings attributed to the expression, see U. Mattei, 'Common Law: Il diritto anglo-americano', in R. Sacco (ed.), Trattato di Diritto Comparato, (Utet, 1992), p. 83.

65. Act of April 17, 1981, ch. 27, in Wash. Laws 112. See $\S 4(1)$ of the Act. See P.A. Talmadge, 'Washington's Product Liability Act', 2 University of Puget Sound Law Review (1981), p. 5.

66. The case clarified this link of causality, see Taylor v. Intuitive Surgical Inc, n. 62. For a deep analysis on the relationship between federal common law and state law see L. H. Tribe, American Constitutional Law, vol. I (New York Foundation, 
Finding, therefore, sufficient material facts to prove the fact, the causal link and the damage due to violation of the duty to instruct provided for by the WPA, the Court considered that it could not accept the summary judgment motion proposed by the defendant and to proceed to trial. ${ }^{67}$

The following year - on 9 June $2014^{68}$ - Taylor attempted to convince the jury that Intuitive Surgical Inc. had failed to provide sufficient instruction regarding the safe use of the robot, not only to the surgeon, but also to the hospital facility at which the surgery took place. The court declined to do so and instructed the jury on whether such a manufacturer's duty existed only to the surgeon responsible for the operation. Further, the court believed that this potential profile of manufacturer liability should be judged under the negligence standard. The jury returned a verdict in favour of the defendant, finding no negligence in instructing and training the surgeon.

In the appeal brought by Taylor, on 7 July $2015,{ }^{69}$ the DC Court upheld the verdict of the jury charged with the task of verifying the existence of liability of the defendant only with reference to omission of instructions to the surgeon, and not also to the hospital. ${ }^{70}$ When, in fact, the device or drug can be used only on prescription, or through the work of the doctor, the conditions are met for the applicability of the theory according to which the surgeon acts as 'guardian' - as described by the court - towards the patient. This conclusion was, however, overturned in 2017, when the Washington Superior Court ruled that such a duty on the part of the manufacturer also exists with respect to the hospital that purchases the robot. ${ }^{71}$

On the whole the so-called 'liability gap' in the field of robotics would stem from the technical and functional features of the same, which presumably undermine the correspondence between the possibility of control, the ability to bypass damage and the relative imputation of liability (see section 3.A). ${ }^{72}$ Among the most evident risks is the potential tendency to transform actions against the surgeon into actions against the manufacturers of the machinery. The patient could sue for liability against the medical professional, and/or against the hospital for having decided to use the robot in the operation that affected him, and the same hospital could sue the manufacturer for product defects. The parameters of strict liability to which the manufacturer is subject would, by their nature, be more favourable to the patient-actor.

2000), p. 475 ff. A key role is played by the preemption doctrine, that derived by the Supremacy Clause (art. VI, § 2 of the US Constitution). See D.G. Owen, Products Liability Law (1st ed., West 2005) which underlined that: 'the defense of federal preemption in recent years has grown from little more than a blip on the radar screen to one of the most powerful defenses in all of products liability law'. Leading case on the applicability of the preemption doctrine in the field of product liability is Cipollone v. Liggett Group Inc., 505 U.S. 504, 508, 530-31 (1992). See also Medtronic v. Lohr, 518 U.S. 470, 474, 503 (1996), in the field of medical devices.

67. See Taylor v. Intuitive Surgical inc., n. 62.

68. Estate of Fred E. Taylor v. Intuitive Surgical Inc., 09-2-03136-5, Superior Court, State of Washington, Kitsap County (Port Orchard), decided on June 9, 2014

69. Taylor v. Intuitive Surgical, Inc., Court of Appeals Cause No. 45052-6-II, 2015 WL 4093346 (Wash. Ct. App.), decided on July 7, 2015.

70. Courts extended the applicability of the learned intermediary rule, $\S 6$ of the Product Liability Restatement to medical devices. Based on this doctrine the pharmaceutical producer's duty to instruct is fulfilled if the producer informs the physician (not the patient). See Piper v. Bear Med. Sys. Inc., 883 P. 2d 407, Ariz. Ct. All. 1993.

71. Taylor v. Intuitive Surgical, Inc., Superior Court di Washington n. 92210-1, (Wash. Feb. 9, 2017).

72. Authors have underlined that a 'responsibility gap' doesn't exist as long as it is always possible to identify the person liable for damages derived by the production and use of intelligent machines. See: A. Bertolini, Study on Artificial Intelligence and Civil Liability, commissioned by Policy Department $\mathrm{C}$ and requested by the Committee on Legal Affairs of the European Parliament, 2020, p. 33, www.europarl.europa.eu/RegData/etudes/STUD/2020/621926/ IPOL_STU(2020)621926_EN.pdf. 
In the course of the following paragraphs, the two problematic profiles will be examined in more detail: the burden of proof of the defectiveness, and the responsibility for lack of or inadequate instructions of the personnel assigned to the use of the robot (duty to train).

\section{A. Robotic surgery malfunctioning and burden of proof: 'old wine, new bottles'.}

Product liability actions have, for the most part, engaged judges in resolving liability without proof of defect: in most cases, in fact, it can only be presumed that it derives from a defect. Consider, for example, the fact that a software update is not always carried out by the same manufacturer, it becomes, therefore, difficult to identify which part of a malfunctioning code was defective $a b$ origine, or has become so during the update.

As a rule, in order to establish such an action, the plaintiff must prove the defect, the causal link between defect and damage, and the existence of the defect at the time of approval and marketing of the product. However, in general, the complexity of technology seems to make material proof of the defect a probatio diabolica and it is, therefore, difficult to identify the cause of the malfunction of a sophisticated device such as a robot. One thinks, for example, of the difficult probative reconstruction of the design or manufacturing defect, given the chain of subjects involved along the supply chain. It should, however, be noted that surgical robots now on the market are able to record all commands received during the operation and acquire, therefore, useful data for the evaluation of the facts occurred. However, this information is not directly accessible to the hospital or the patient, thus limiting the possibility of obtaining crucial evidence in actions against the hospital, the manufacturer or the surgeon. This is a profile that would deserve to be regulated so that the patient, his or her attorney, and all parties best able to analyse the incident, can have access based on a simple request.

In any case, for the criticalities described in the Silvestrini case, the intent of the damaged party to distance himself from the traditional theories based on the proof of the defect of the product is clear, in order to configure the responsibility of the producer even in its absence.

This means that if the plaintiff is unable to provide such direct evidence, then under this theory the evidence of the product's malfunctioning acts as proof of the product's flaw. This is the so-called malfunction doctrine, a corollary of res ipsa loquitur (Restatement Second of Torts $\S$ 328D), governed by $\S 3$ of the Third Restatement of Torts dedicated to 'Circumstantial evidence supporting inference of product defect' ${ }^{73}$

Particularly with regard to the type of malfunctions which occur in the cases under examination, it should be remembered that, according to the Third Restatement of Torts $\S 2$ (comment $\mathrm{f}$ ) of 1998 , the evaluation of the defect in the design of the product is made by comparing it with what would have been the reasonable alternative design (RAD): an ideal comparison parameter, probably available at similar costs to the one which is the object of the malfunction, on the basis of which the responsibility of the designer for the defect in the actual product is established if it appears that the risks could have been avoided by designing the product differently. ${ }^{74}$

73. This is the circumstantial burden of proof, see Restatement (Third), Torts, Products Liability § 3, p. 111, 1998. The original ruling stated: 'it may be inferred that the harm sustained by the plaintiff was caused by a product defect existing at the time of sale or distribution, without proof of a specific defect, when the incident that harmed the plaintiff: (a) was of a kind that ordinarily occurs as a result of product defect; and (b) was not, in the particular case, solely the result of causes other than product defect existing at the time of sale or distribution'. 
However, the RAD criterion is becoming increasingly vague in the context of innovative technologies. ${ }^{75}$ It is the reference to 'reasonableness' that would seem to be no longer appropriate. In the US context, the plaintiff would need a highly skilled expert to understand how the alternative algorithm could have been 'written' (programmed), in a more secure way, and therefore suitable to prevent the accident. And in any case, due to the complexity of the procedure, the cost and the difficulty of finding such an expert, this type of operation is often not feasible.

In this circumstance, it is difficult for the manufacturer to assess the likelihood of a damaging event occurring and when it is the result of an action performed by the machine, by virtue, for example, of machine learning. ${ }^{76}$

This would involve monitoring what manufacturers and programmers are coding. This is not a simple operation, since, as Frank Pasquale observes - in his book The Black Box Society - many architectures of digital systems are veiled by absolute secrecy: ${ }^{77}$ it is impossible to understand what happens in the black box of the algorithm. ${ }^{78}$ To ensure monitoring, legislators should then establish rules and guidelines for programming and their interactions. ${ }^{79}$

Some American researchers, for example, have proposed to investigate, in a deeper way, or in a different way than the traditional way, the applicability of the criterion of reasonableness to the algorithm, since the same is not immune from prejudice being designed by a man with his own desires, values and ethical principles: it is called 'reasonable algorithm', which recalls the standard of the reasonable professional.

Establishing its content and what differentiates it from that applied to human action is the subject of interesting debates. Intuitively, the high potential of algorithms would lead to identify, as a reference parameter for evaluating their functioning, 'qualified' reasonableness. However, subjecting the algorithm to an analysis of the behaviour or choices of a hypothetical professional may seem improper, as it would 'personify' the machine.

In any case, going back to the admissibility of evidence by circumstances, it should be remembered that, despite the historical aversion of the jurisprudence of many states to the application of res ipsa loquitur in the field of product liability, in the last 50 years the courts have admitted evidence by circumstances of malfunctioning, to which injured parties have appealed in an increasingly consistent manner, ${ }^{80}$ so much so that this has led part of the doctrine to warn about the potentially

74. See Restatement Third $\S 2$ (comment $\mathrm{f}$ ) del 1998: 'product is defective in design if the reasonable risks of harm could have been reduced by a reasonable alternative design'.

75. See S. Chopra and L.F. White, A Legal Theory for Autonomous Artificial Agents (University of Michigan Press, 2011), p. 139; A. Davola, 'A Model for Tort Liability in a World of Driverless Cars: Establishing a Framework for the Upcoming Technology', 54 Idaho Law Review (2018).

76. J.M. Balkin, '2016 Sidley Austin Distinguished Lecture on Big Data Law and Policy: The Three Laws of Robotics in the Age of Big Data', 78 Ohio St. L. J. (2017), p. 1217.

77. F. Pasquale, The Black Box Society (Harvard University Press, 2016).

78. This is a new situation as it is analogous to what happened in case of misrepresentation, civil conspiracy, and violation of Racketeer Influenced and Corrupt Organizations (RICO) in the case of negligent marketing. Cf. D.G. Owen, Products Liability Law.

79. F. Pasquale, 'Toward a Fourth Law of Robotics: Preserving Attribution, Responsibility, and Explainability in an Algorithmic Society', 78 Ohio St. L.J. (2017), p. 1243.

80. The same legal literature identifies the malfunction theory with the expression of 'indeterminate defect theory', or 'general defect theory', or simply 'a principle of circumstantial evidence'. See D. Owen, 'Manufacturing Defects', 53 S. C. L. Rev. (2002), p. 851. See also G.T. Schwartz, 'The Passage of Time: The Implications for Product Liability: New Products, Old Products, Evolving Law, Retroactive Law', 58 N.Y.U.L. Rev. (1983), p. 796. Metro. Prop. \& Cas. Ins. Co. v. Deere \& Co., 302 Conn. 123, 135 (Conn. 2011). The restricted approach is adopted also by the decision 
'disastrous' effects to which such admission could lead, appreciating the restrictive approach of some state courts on the subject.

The conditions which legitimize the operation of the pro-actor mechanism under examination are three: the indication that the malfunctioning, in all probability, stems from one of the three types of defects examined (manufacture; design; information); the absence of the occurrence of secondary causes; and the absence of abnormal use.

In competing cases, the courts have clarified the relationship between an action for damages for malfunction of a medical device and an action for damages for professional liability of the doctor. ${ }^{81}$ in Rogers v. Johnson \& Johnson Products, for example, a patient sued for damages suffered as a result of second and third degree burns during the plastering of a broken leg. ${ }^{82}$ The plaintiff alleged cumulative liability on the part of the hospital and its medical staff for negligent preparation of the cast and strict liability on the part of the manufacturer for inherent defect and malfunction of the material supplied to make the cast. The defendant objected to the dismissal of both claims. The Superior Court of Pennsylvania had accepted the hospital's arguments, according to which, if the court determines that the evidence provided by the plaintiff is sufficient to establish medical liability, it must, consequently, exclude that the plaintiff establishes a prima facie case of liability on the basis of malfunction theory. If, therefore, the negligent medical service is proved, it is no longer possible to apply the malfunction theory, since human conduct represents an independent and supervening cause of damage, sufficient to exclude the configurability of liability for product malfunction. ${ }^{83}$

In any case, taking a more general perspective on the case in question, it emerges that this evidentiary facility may not help the patient when the malfunction is of the Da Vinci. In Mracekv. Bryn Mawr Hospital, for example, the fact that the display had repeatedly indicated 'error' was considered by the court to be insufficient 'to clearly see a product defect'. ${ }^{84}$

Some authors, with specific reference to the use of the malfunction theory in the field of surgical robotics, suggest the opportunity to adopt a 'facilitated' version of the theory in order to consider it still a tool that meets the needs of technological progress in the light of the reasons of social policy that have historically influenced the responsibility of the manufacturer, i.e. admitting that the proof by circumstances is satisfied only by excluding abnormal or unreasonable use and without requiring the plaintiff to allege the absence of secondary causes; it will then be up to the manufacturer,

Martin v. E-Z Mart Stores, Inc., 464 F.3d 827, 830-831 (8th Cir. 2006); and Harrison v. Cairns Pontiac of Marlow Heights, Inc., 77 Md. App. 41; 549 A.2d 385 (1988). The theory confirmed the current expansion of civil liability. In literature see G. Ponzanelli, 'L'imperialismo della responsabilità civile', Danno e responsabilità (2016), p. 221.

81. Some authors advised that the extensive application would transform producers into insurance agents: B.H. Raymond and L.H. Allen, 'Malfunction Theory as a Triple Threat for the Defence', 80 Def. Couns. J. (2013), p. 297. So they appreciated the restricted approach of some state courts. A similar question was faced also on the European system with the judgement of the European Court of Justice, Grand Section, 21 December 2011, no. 495, 10 Danno e resp. (2012), 957, with a note by Frata L. Il danno da prodotto difettoso nelle prestazioni sanitarie: la corte di Giustizia e l'armonizzazione 'totale'. The Court had been asked by the Conseil d'ètat the following question: whether the French regime of strict liability of hospitals could coexist with the EU rules on product liability. The decision strictly excludes that the liability of the hospital, as user of the defective product in the context of the provision of patient care, falls within the scope of the Directive 85/374/CEE on producer liability.

82. Rogers v. Johnson \& Johnson Products, Inc., Superior Court of Pennsylvania, No. 01037 Philadelphia 1986, (November 6, 1987).

83. Casenote: 'Products liability: alternative theories of strict liability 'malfunction' and medical malpractice cannot be simultaneously considered by jury', 21 American Health Lawyers Association, Journal of Health Law (1988), p. 3.

84. Mracek v. Bryn Mawr Hosp. and Intuitive Surgical Inc., see n. 57. 
according to the burden shifting mechanism, to allege the proof of the existence of specific secondary causes with a 'totally of the circumstances approach'. 85

On the whole, as hinted by the title of the current section, the different profiles of the burden of proof are, at a general look, not novel issues in this sphere. Anyhow, they turn out to 'enriched', and in some way more intricate to manage in virtue of the peculiar robotic features. So far, the US analysis pertaining the burden of proof offers to the ongoing EU debate the identification of the following critical topics: (i) the matter of the evaluation of the design defect based on algorithm; (ii) the criticalities of understanding the opportunity or inopportunity to permit the operability of the malfunction theory in robotic products litigation; (iii) the challenges stemming from the plurality of different components and different subjects responsible for their safety (see section 4).

\section{B. Regarding the need for innovation in medical training and instruction: a taste of novelty}

The most recent US cases have identified a different origin of the problems: not so much malfunction by itself, but insufficient experience of the surgeon in using the technology. There are no specific qualifications for the surgeons intervening through surgical robots, though the operation of such machines differs meaningfully from conventional surgery. For example, appropriately dealing with the 3D visuals produced by the system and commanding manipulators with seven levels of discretion entails training. Not surprisingly, in the US, several lawsuits have been filed against Da Vinci's manufacturer, arguing that the company has supplied insufficient training to surgeons before using the robot. Notwithstanding this, it is not the first time that US host many medical suits and whether or not the surgical robots embody something special in this case is intricate to state without going through the medical claims. ${ }^{86}$

The acquisition of new skills and technical knowledge is an essential prerequisite for surgeons to use robotic equipment.

It is in the Taylor case that the plaintiff's action against the manufacturer is based on the defect of instructions and training given to the surgeon who used the robot and addressed to the hospital that purchased it. $^{87}$

In this way, distancing himself from the field of professional liability of healthcare personnel, and from the more traditional field of product liability, the plaintiff identifies a profile of liability of the manufacturer that is entirely specific to the marketing of the most sophisticated medical devices: the duty to instruct and train medical personnel.

85. C. Beglinger, 'A Broken Theory: The Malfunction Theory of Strict Products Liability and the Need for a New Doctrine in the Field of Surgical Robotics', 104 Minn. L. Rev. (2019), p. 1041. B.H. Raymond and L.H. Allen, 'Malfunction Theory as a Triple Threat for the Defence', 80 Def. Couns. J. (2013), p. 297.

86. From a legal point of view, in Europe, Da Vinci like surgical robots are qualified as a Class IIb medical device based on Annex IX of Council Directive 93/42/EEC of 14 June 1993 (Medical Devices Directive, which is foreseen to be replaced by the Regulation of the European Parliament and of the Council on medical devices 2012/0266 (COD)). Council and Parliament agreed on a final text on 15 June 2016; final formal adoption is expected during the first semester of 2017: see https://ec.europa.eu/growth/sectors/medical-devices/regulatory-framework/revision_en. This Directive aims at regulating safety of medical devices and basically determines that products that have a CE marking are allowed on the EU market. Class IIb products need to undergo the procedure for declaration of conformity (Annex II, full quality assurance) or type-examination (Annex III).

87. Taylor v. Intuitive Surgical, Inc., Court of Appeals Cause No. 45052-6-II, decided on 7.07.2015; Silvestrini v. Intuitive Surgical, Inc. et al., decided by the Louisiana Eastern District Court il 6.02.2012. 
In this regard, the key issue addressed extensively by the DC Court of Appeals in $2015^{88}$ relates to the identification of the parties to whom such instruction and hands-on training provided by the manufacturer of the surgical robot should be directed.

There is no doubt that the first identified party is the medical professional. Given the concrete circumstances of use of the product, the physician, with his expertise and knowledge of the specific clinical case, acts as a 'learned intermediary hand', because he is better able than anyone else to understand, interpret and transfer the information from the manufacturer to the patient he has taken care of.

It should be kept in mind that, beyond the information found on websites, consumers generally do not know the characteristics of medical devices, therapies, or surgical treatments until they become patients. ${ }^{89}$ Furthermore, unlike the marketing of pharmaceuticals, for which information and instructions are a mandatory part of the packaging, the package of devices very often does not directly enter the sphere of knowledge of the patient. And just like consumers, physicians have a more limited knowledge of medical devices than of drugs. For devices, then, there is no equivalent of the Physician Desk Reference popular for drugs. ${ }^{90}$

Surgical robots are among the most widely advertised products by US medical centres and the medical personnel who have them. They differ from other devices in that the likelihood that they will 'fail' depends not only on the intrinsic peculiarities initially described, but also on the skills of the person using them, the characteristics of the patient, the possible occurrence of 'bugs' in the system, and the equipment available at the healthcare facility in which they are used.

For what it concerns the phases of marketing, advertising and post-market assistance, in spite of the undisputed obligation of the manufacturer to transmit correct information and practical training to the surgeon, the 'quantum' of such instructions and the modalities of the same is still the subject of debate. ${ }^{91}$ This is not surprising if we consider that, for many advanced robotics applications, the determination of precise safety standards that can satisfy the complex operational scenarios in which robots are protagonists is still under discussion. ${ }^{92}$

88. Taylor v. Intuitive Surgical, Inc., cit., see note 63.

89. Most class II and class III devices are subject to prediction and their labelling must meet FDA requirements. In summary, surgical robot information for the consumer audience should: contain the exact name of the device and a brief illustration of the appropriate uses, safety warnings and precautions, adverse effects, and contraindications to the use of the device. Among the requirements, the Agency expects that adequate warnings about the appropriate use of the device will be included. Within this typology, a more restricted group of devices, including surgical robots such as the one under consideration, are subject to additional requirements on sale, use, distribution and information, imposed by FDA, where it has jurisdiction. If, as noted, under Section 510, the device is subject to an abbreviated approval process, the FDA will automatically lack jurisdiction over it.

90. E.g. the Physician Desk Reference (PDR), PDR Network; 2012th edition (December 27, 2011).

91. See L. Noah, 'The Products Liability Restatement: Was it a Success? This is Your Product Liability Restatement on Drugs', 74 Brooklyn L. Rev. (2009), p. 839. With specific reference to the Da Vinci robot malfunction cases, a legal weekly reported the arguments of the various pending court cases. Among these, it was pointed out that the surgeons who are given instructions to use the Da Vinci are already familiar with laparoscopic techniques, so it would be difficult to determine how much and what additional instruction is needed for them to accomplish full control of the device. Cf. D.J. Levy, 'Robot Conflict: Product-liability Suits over Surgical Device Could Lead to Med-mal Actions', Michigan Lawyers Weekly, 27 July 2012.

92. On the standardization for robotics see G.S. Virk, 'The Role of Standardization in the Regulation of Robotic Technologies, in E. Palmerini and E. Stradella, Law and Technology: The Challenge of Regulating Technological Development (Pisa Press, 2013), p. 311. 
The problem of determining information content emerges in the arguments of the parties' counsel and in the opinions of the judges in Taylor v. Intuitive Surgical Inc. Taylor's counsel argued that the defendant mistakenly believed that the surgeon was ready to operate the $\mathrm{Da}$ Vinci robot after performing only two simulated robotic operations under the guidance of a supervisor and one day of training at the manufacturer's facility. This training course was what appeared as 'best practices' in the company documents drawn up - according to what the plaintiff's lawyer stated - by a director who could boast previous working experience in the world of wines, but not in the world of medical products. The defence of the defendant-producer, instead, argued that the surgeon should not have undertaken the operation in robotic surgery in this case, as the patient was obese and had already been operated on many times, conditions that were considered, according to the instructions given, preclusive of robotic surgery. The Court of Appeals, accepting the latter argument, did not find the manufacturer liable for insufficient training of the surgeon and held the latter liable for negligent conduct. In other words, it is not a question of objective responsibility, since the judges observe that, in the field of medical products, the risks which then actually occur depend on the individual characteristics of the patient as well as the characteristics of the device, as assessed by the qualified surgeon. It must be considered that the manufacturer refers this judgment to the surgeon involved since, necessarily, it must be done on a case-by-case basis. ${ }^{93}$

The usual university training does not yet allow clinicians to gain sufficient experience in the use of complicated surgical robots. In medical schools, the pharmacology courses available from the first years of university are not matched by specific training in the use of surgical devices and technologies.

The public debate regarding the use of non-traditional devices that exploit the potential of artificial intelligence focuses on the type of training that is appropriate, and questions whether new practices should be introduced alongside traditional ones.

An interdisciplinary reading of the topic at hand offers important insights on this front. A two-year empirical study of five US hospitals in several states found that the surgeons most skilled in the use of the Da Vinci robot did not follow a standard practice but trained in shadow learning, a set of practices not in line with traditional medical practice and standards. It is also true that the radically different modes of operation of robotic surgery greatly limit the possibilities of collaboration among residents, making standard training methods ineffective. Shadow learning is based on three pillars: (a) a specialization from the beginning of the professional career instead of a more general preparation; (b) a 'theoretical' preparation when an empirical one is generally required (e.g., training basic skills through a rudimentary computer simulation); (c) the possibility to practice with the robotic equipment without the guidance of a supervisor. ${ }^{94}$ The conclusions of the study seem, in some ways, provocative because they are in contrast to the traditional practice of training medical personnel: the medical practice of training new surgeons with the methods used in traditional surgery is inadequate, as the current literature suggests.

Indeed, these empirical observations suggest that the acquisition of new skills is a natural consequence of the new way of working that technologies imply. The fact that this adaptation occurs at the organizational level is not in itself sufficient to guarantee the full usability and high level of

93. ' . . with medical products, the risks depend as much on the patient's individual circumstances, as assessed by a qualified physician, as the qualities of the product itself and the manufacturer defers to the doctor's judgment' (Taylor v. Intuitive Surgical Inc., n. 62).

94. M. Beane, 'Shadow Learning: Building Robotic Surgical Skill When Approved Means Fall', 64 Adm. Sci. Quarterly, (2019) - see table in the article. 
security of a new technology. The next step is necessary: to fully realize technological progress, the scientific community must ensure that those who will apply the results of the progress are adequately prepared.

For the purpose of completeness, it is worth including in the current section the analysis of the producer's duty to instruct direct to the hospital, as the structure is responsible for having purchased the robot. In the Taylor v. Intuitive Surgical Inc appeal, in fact, this further profile was discussed for its legal and enterprise social accountability.

The appellate courts narrowly interpreted the rationale behind the WPLA, stating that the learned intermediary doctrine does not apply to the person who pays for or owns the robot, but only to those who are able to evaluate the patient's medical history to make a personalized medical judgment, depending on the case assigned to them.

Therefore, under the WPLA, the manufacturer fulfils its duty by transferring warnings and providing training to only learned intermediaries, i.e., physicians.

In line with the dissenting opinion of one of the three judges of the court of appeal, this interpretation seems to act as a shield with respect to the identification of the manufacturer's responsibilities, encouraging him not to 'disseminate' information about the risk profiles of the medical equipment purchased by the hospital. ${ }^{95}$ This effect would not only be contrary to the general rationale of marketing duties, but also to the 'proactive' attitude that the American system constantly requires from the manufacturer, intensifying this obligation when dealing with 'unavoidable unsafe' products, or those obtained with advanced technologies for which there is not yet a consolidated medical practice. ${ }^{96}$

The solution originally offered does not seem a good reason to share it, considering the fact that usually - in fact almost always - the first contact of the patient does not take place with the surgeon but with the staff of the facility, who, although not generally familiar with the mechanisms of use of robotic surgery, are the recipient of many questions and doubts of patients.

Often, moreover, the hospital advertises the use of the surgical robot through its website, thus attracting the attention of many potential patients looking for answers about the risks and benefits of such use.

In this regard, a recurring problem that arises when promoting information and warnings about new implantable devices concerns the level of accuracy of these warnings, as there are still no predefined parameters to identify the content. The clearest indications concern only temporarily implantable robotic devices, or the availability of advanced laparoscopic techniques, as a key content in the advertising of advanced oncological, gynaecological, urological and cardiological surgery programs, the main profit areas for hospitals, specialized medical centres and groups of surgeons.

In these settings, robotic applications have been publicized for more than five years. Data on business practices are not encouraging and highlight the fact that the primary information channel for promoting surgical robot use is telematics. A study presented in 2012 at the American Congress of the Society of Gynecologic Oncology, for example, analysed the content,

95. The judge Lisa R. Worswick's dissenting opinion considers the hospital that bought the robotic surgery application requires the producer to instruct and train the same buyer: 'because the physician does not stand between manufacturers and unwarned hospitals, the physician does not protect the unwarned hospital' (Justice Worswick). Consequently the learned intermediary doctrine does not relieve the manufacturing company of the duty to train and educate hospitals that purchase the product.

96. The Second Restatement of Torts $\S 402$ A cmts. i, k (1965) recognized the existence of unavoidably unsafe products. 
quality, and accuracy of information about the use of robotic surgery in gynaecology found on the websites of prestigious hospitals. ${ }^{97}$ The results of the survey indicated that only in less than $15 \%$ of cases were the claims about the 'superiority' of the surgical robot over traditional techniques supported by scientific data. Information regarding cost, complications and operation time compared with conventional surgery was rare. The study therefore concluded that the information disseminated via web by hospitals about the availability and use of surgical robots was not in line with the FDA requirements and did not adequately present the alternative procedures and safety profiles related to the techniques.

The problem that arises in the Taylor case with regard to the lack of training of the hospital would, in fact, concern a specific profile inherent in the defects that afflict the marketing phase of the product. The defect would, therefore, affect the safe and effective use of the product and the adequacy of both the warnings and the instructions relating to the product.

It becomes essential, therefore, to understand how to deem instructions and warnings issued by the manufacturer to be sufficiently adequate. To this end, there are many parameters of judgment that have been tried so far. The most common is the risk-benefit analysis. Many courts state that the analysis of manufacturing defects and those inherent in the marketing phase must be based on the assessment of risks and techniques used to avoid them, among those that can be legitimately expected at the time of distribution. ${ }^{98}$ A part of the doctrine emphasizes, however, the need for a counterfactual judgment, from which to deduce that the information or technical instruction omitted was precisely what was necessary to avoid the damage occurred. ${ }^{99}$ However, this judgement criterion would risk invalidating the risk-benefit analysis, since in all cases the additional instruction (the missing one) could appear less costly than verifying the degree of foreseeability of the reified risk.

All of these contradictions appear to have been incorporated by the Washington Supreme Court in the last instance of the 2017 Taylor v. Intuitive Surgical case, reforming the decision of the Court of Appeals, and including the hospital facility purchasing the robot. ${ }^{100}$ In practice, hospitals must ensure that medical staff are properly trained, as well as the appropriate safety standards for patients, even though there is no direct relationship with them. ${ }^{101}$ Especially with reference to extremely complex products, it seems necessary to ensure that even the hospital itself is the recipient of the

97. The study is proposed by M.B. Schiavone et al, 'The Commercialization of Robot Surgery: Unsubstantiated Marketing of Gynecologic Surgery by Hospitals', 207 Am. Obstetrics \& Gynecology (2012), p. 174. The paper analysed the websites of New York, Pennsylvania, Georgia, Illinois, Colorado and California.

98. Many courts affirmed that for an efficient system of liability assessment it is necessary to balance risks and benefits. See Ruiz-Guzman v. Amvac Chem. Corp., 7 P.3d 795, 807. On the topic see M.Z. Edell, 'Risk Utility Analysis of Unavoidably Unsafe Products', 17 Seton Hall L. Rev. (1987), p. 623.

99. C.E. Cantù, 'Distinguishing the Concept of Strict Liability for Ultra-hazardous Activities from Strict Products Liability under Section 402A of the Restatement (Second) of Torts: Two Parallel Lines of Reasoning that Should Never Meet', 35 Akron L. Rev. (2001), p. 1.

100. Taylor v. Intuitive Surgical, Inc., Superior Court of Washington n. 92210-1, Wash. Feb. 9, 2017. The judgement stated that the WPLA does not specify who should receive these warnings. However, it states that '[a] product is not reasonably safe because adequate warnings or instructions were not provided with the product ...' On one hand, the statute discusses inadequate warnings owed 'with the product' for products where, at the time of manufacture, there was a likelihood the product would cause the plaintiffs harm. On the other hand, it discusses that warnings provided after the product was manufactured be given to 'product users'. Ibid. at (1)(c). Since the product is owned and maintained by the purchasing hospital, it follows from the text of the statute that the purchaser is owed product warnings with the product it purchases' (p. 12).

101. Howell v. Spokane \& Inland Empire Blood Bank, 114 Wn.2d 42, 55, 785 P.2d 815 (1990). 
instructions provided by the manufacturer, also by virtue of the duty of care that they have towards their patients given the 'public's perception of the modern hospital as a multifaceted health care facility responsible for the quality of medical care and treatment'. ${ }^{102}$

The DC judges point out that the health care facility staff is directly involved in training the surgeons who employ the robot. The health care facility simply cannot maintain the high safety standards required by law if manufacturers are exempt from the duty in question with respect to itself.

Concluding this section of the article, one can observe that the profile of the duty to train and to instruct (iv) embodies a novel issue in the litigation sphere and, certainly, it pertains to the contemporary landscape of the technological medical equipment. The empirical outcomes discussed above would offer food for thought to the European discussion about the need, and possibly few insights about the modalities to develop through awareness and culture of AI (see sections 4 and 5).

\section{Back to the European landscape, with the benefit of the US experience}

The US litigation on robotic surgery presented an articulated framework of the range of issues: some of them were already identified issues that have been sharpened by the robotic technology, whereas others entered the courts for the very first time.

Due to the fact that well-known legal, cultural and policy divergences characterized the EU and US contexts, an automatic comparison is not feasible, so this article wishes to consider the liability issues identified up to now in order to reflect on their potential management and regulation in the European framework and in the light of the recent AI Act previously described (see sections 2 and 2.A). The wish is to provide some useful remarks to create a homogeneous landscape in order to face the global challenges of contiguous markets. ${ }^{103}$

Regarding all the issues connected to the burden of proof in robotic surgery we can observe - in European perspective - the following situation, identified under sub-headings for sake of clarity.

\section{A. The design defect}

The issue of the design defect (section 3.A) is not new, even in European medical technology case law, and it is likely to become a crucial problem. ${ }^{104}$ Recent EU documents have already considered it for reflecting on the backcloth of the two coordinated bodies of legislation. ${ }^{105}$

Considering the advanced surgical robot that will present the embedded of an advanced machine learning (e.g. robotic assistant), we have to note that even if algorithms and robots are the product of human creation, the producer and the developer may be unable to predict the way in which the algorithm may respond to all possible conditions regardless the original design. However, it is appropriate to say that ultimately machine learning stays under humans' control if one considers that

102. Pedroza v. Bryant, 101 Wn.2d 226, 232-33, 677 P.2d 166 (1984).

103. See also N. F. Frattari, 'Robotica e responsabilità da algoritmo. Il processo di produzione dell'intelligenza artificiale', 1 Contratto e impr. (2020), p. 458.

104. For this reason, some US legal scholars affirmed that robot liability would be based on an AI's behaviour rather than its design defect due to system complexity or limited explainability. The discussed solution is offered by R. Abbott, The Reasonable Robot: Artificial Intelligence and the Law, (Cambridge University Press, 2020), p. 51.

105. All documents are gathered together on the website of the European Union Agency for Fundamental Rights: https://fra. europa.eu/en/themes/artificial-intelligence-and-big-data. 
the ability to perform is related to the design, dataset and the programming and that the operating system may be constantly controlled remotely. ${ }^{106}$

Focusing on teleoperating robotic systems, the perspective is to consider the issue of the design defect within the AI Act framework. In these terms, up to now the surgery applications have not the features of the high-risk AI applications. This means that the assessment of its design will be conducted on the basis of the harmonized rules already in force, because, even when complementary, AI risk provisions are not enforceable, and it has been assumed that product liability will gain much more relevance for robotic products.

Generally speaking, notwithstanding the elementary range of robotic autonomy, many profiles of the traditional rules on product liability will have to be assessed, such as, for example: the usefulness of expanding the notion of product; ${ }^{107}$ the fact that the use of traditional general standards as 'reasonable person' for the liability assessment is questionable; ${ }^{108}$ and the need to reconsider the proof of defectiveness. ${ }^{109}$ In particular, the re-examination of the types of defects and the criteria for the assessment of new products is a major need in the framework of the revision of the Directive. This re-examination will set up an effective, coherent and 'technologically neutral' system to prevent accidents as far as possible.

In this regard, it has been noted that generally speaking, the Product Liability Directive 85/374/ EEC, which is subject to periodic review, was found in the last official assessment to be still effective overall after adaptation, but due to the functional traits peculiar to algorithms the European Commission has appointed two expert groups - one to review the Directive, the other to study liability issues raised by emerging technologies ${ }^{110}$ - to assess to what extent it is necessary to update the legislation in force and to develop guidelines.

106. F.P. Patti, 'Machine Learning and European Product Liability', in A. Janssen and H. Schulte-Nolke (eds), Researches in European Private Law and Beyond. Contributions in Honor of Reiner Schulze's Seventieth Birthday (Nomos, 2020), p. 107.

107. A software whose functioning causes damage, for example, might not be considered a product, but rather a service, and this would therefore exclude the applicability of the Directive. Current legal research has, in fact, begun to question whether the notion of defect can be applied to the algorithm per se. In practice, the question arises as to whether it is appropriate to identify the product incorporating the AI in its physically, i.e. the algorithms, as the object of malfunctioning.

108. Some authors argue that where a supplier can show that an autonomous computer, robot, or machine is safer than a reasonable person, the supplier should be liable in negligence rather than strict liability. The negligence test would focus on the computer's act instead of its design, and in a sense, it would treat a computer tortfeasor as a person rather than a product. Negligence-based liability would incentivize automation when doing so would reduce accidents, and it would continue to reward suppliers for improving safety. See R. Abbott, 'The Reasonable Computer: Disrupting the Paradigm of Tort Liability', 86 GEO. Wash. L. Rev. (2018). See also R. Abbott, The Reasonable Robot: Artificial Intelligence and the Law.

109. The impact that machine learning can have is intuitable, at least in making the development risk defence outdated (Article 7(e) Directive 85/374/EEC), for the specific field examined. Article 7(e) of Directive 85/374/EEC provides that a producer is exonerated from liability if the state of scientific and technical knowledge at the time at which the product was put into circulation was insufficient to uncover the defect. As is well known, the clause aims at avoiding deterrence from investing in new products and technological innovation. Nevertheless, the practical effect to shift the risk of injury onto the victim and not onto the manufacturer could be dramatically increased due to the development of technology. See concerns about the drawbacks of the clause with regard to autonomous systems: L.Y. Lim, Autonomous Vehicles and the Law (Edward Elgar, 2018), p. 84.

110. Expert Group on Liability and New Technologies - New Technology Formation, Report on Liability for Artificial Intelligence and Other Emerging Digital Technologies, 2019. In its 2019 position paper, the Expert Group notes that current national contractual and non-contractual liability regimes provide only a minimum level of protection in 
With specific reference to the design defect, the case history certifies that the lack or inadequacy of the design as a defect-type will emerge more often for hi-tech products: ${ }^{111}$ most of the algorithm design defects give rise to computer malfunction and question the evaluation criteria applied in Europe, which seems to proceed by accepting and emphasizing the distinction between 'manufacturing defects' and 'design defect' in the wake of the Anglo-American model. ${ }^{112}$ In this context, for example, the patient may be able to prove the design defect of the Da Vinci by claiming that the way the surgical tips were designed creates an increased risk of burns.

\section{B. The malfunction theory}

The second finding of the previous analysis, namely the need to lighten the burden of proof through the malfunction theory, is of pivotal relevance. Robotic applications are based on data about the functioning of the statistical logic: the malfunction of the design defect is theoretically based on the calculation of the 'deflection' from the average expected operation that allows to assess the existence of a design defect.

This is a step that deserves attention since, at present, it is envisaged only by some pioneering studies on the subject, which effectively argue as follows: ${ }^{113}$ comparing the final result of two algorithms on the market to deduce the defectiveness of one is probably the most obvious way, certainly the one that would dictate the American legal tradition. However, the method is not convincing, since two algorithms designed to perform the same task could work according to a different mathematical process, and deal with the same situation in different ways.

In other words, even in the European perspective it emerges that a criterion for evaluating a design defect of the algorithm should be sought in the average value of their result, taking into account that if one algorithm works more efficiently than another, this does not mean 'tout court' that the latter is defective: the standard of defectiveness, therefore, cannot be that of 'not as good as the best algorithm on the market'.

In virtue of these considerations, a criterion that would seem essential for the EU Commission to take into account in revising the concept of defectiveness could be the statistical one, identifying as

cases involving new technologies. Indeed, some features of emerging technologies impact essential elements of the case, e.g. making the evidentiary position of the injured party difficult.

111. We agree with A. Bertolini, 'Robot as Products: the Case for a Realistic Analysis of Robotic Applications and Liability Rules', 5 Law, Innovation and Technology, (2013), p. 214.

112. Albeit it is not possible to make a clear comparison in this matter due to the structural diversity of the two systems European and American - it clearly emerges that the European discipline has been influenced by the American model: the reference to the product defect as the central nucleus of responsibility is analogous; just as analogies emerge in the operational solutions in terms of products complying with standards. It is also true that these models differ in important respects, both in the architecture of the defect, and with regard to the relative burden of proof. The Third Restatement classifies defects into three distinct categories, with heterogeneous burdens of proof depending on the type of defect. This solution is not present in the text of the European Directive and, although sometimes adopted by our jurisprudence, has not led to a differentiation of the burden of proof. With a view to lightening the burden of proof on damaged consumers, other significant differences emerge: only the Restatement provides that the damaged party can dispense with the proof of the defect, when specific 'circumstances', including the exclusion of other possible causes of damage, allow the judge to presume the existence of a defect. Circumstantial evidence assumes particular raised by the malfunctioning of the algorithm, where a series of presumptions would allow the defect to be deduced from the damage, in the absence of other causes to which the damage in question could be attributed.

113. J.S. Borghetti, in S. Lohsse et al., Liability for Artificial Intelligence and the Internet of Things, Münster Colloquia on EU Law and the Digital Economy IV (Hart Publishing, Nomos, 2019), p. 63. 
a reference a 'threshold' value of efficiency $(\mathrm{X} \%)$ below which the algorithm could be considered malfunctioning, ergo defective.

\section{The complexity of Al medical applications and the plurality of actors}

Discussing the third finding (see section 3.A) about the issue of the plurality of components, actors and need of transparency also finds a parallel trend going on Europe. Even in future advanced medical robotic applications the most impressive challenges for the present EU liability model will relate to machine learning where functioning is based on a complex interrelation of components whose design and production is the responsibility of different actors. The different parts of robotic surgery are based on mathematical models of a sample of data, and they could effectively perform a specific task in an unpredictable way based on data processing. In general terms, 'complexity' has been identified as a technical component, ${ }^{114}$ both in its inherent meaning (e.g. opacity), and 'external', that is to say, reliant on the interaction with the digital context in which the application is located.

The Product Liability Directive rules should be revised to better ensure a fair distribution of risks among the various subjects involved. ${ }^{115}$ Along the chain of production, distribution and use of the multiplicity of components, software, systems or services, which together form the new technological ecosystems, there are many economic operators involved. For example, those who update software for products already on the market are usually different from the manufacturer.

Recent European ongoing academic debate pointed out the importance of regulating the phenomenon of 'complexity': it is important to think about a potential transformation of the liability system, designing a digital ecosystem for liability where the damaged consumer/user/patient can be refunded even when it is not possible to precisely allocate responsibility due to the complexity of the robotic application and the several intervened actors. ${ }^{116}$

\section{The duty to train and instruct}

Lastly, concerning the emerging profile of the need for innovation in formation and training (section 3.A) for those who use medical robots, there is not yet any specific debate or provision at the EU level. In any case, some general remarks stated in the AI Act for the development of high-risk AI systems indicate the need for certain actors, such as providers, notified bodies and other relevant entities, such as digital innovation hubs, testing experimentation facilities and researchers, to

114. The Expert Group observed: 'modern-day hardware can be a composite of multiple parts whose interaction requires a high degree of technical sophistication. Combining it with an increasing percentage of digital components, including AI, makes such technology even more complex and shifts it far away from the archetypes of potentially harmful sources on which the existing rules of liability are based. Where, for example, an AV interacts with other AVs, a connected road infrastructure and various cloud services, it may be increasingly difficult to find out where a problem has its source and what ultimately caused an accident. The plurality of actors in digital ecosystems makes it increasingly difficult to find out who might be liable for the damage caused. Another dimension of this complexity is the internal complexity of the algorithms involved'. Expert Group on Liability and New Technologies - New Technology Formation, Report on Liability for Artificial Intelligence and Other Emerging Digital Technologies, 2019, p. 32.

115. A. Bertolini, Study on Artificial Intelligence and Civil Liability, p. 62.

116. This was underlined by Teresa Rodríguez de las Heras Ballell, Is the Product Liability Directive poised to accommodate smart products? Product Liability for Beyond-Product Ecosystems, during the Münster Colloquia on EU Law and the Digital Economy, Smart Products, cit. 
access and use high-quality datasets within their respective fields of activities. ${ }^{117}$ This will imply the development of the abilities necessary to cope with the opacity that might make certain AI systems.

Moreover, at a more general level, due to the disruptive nature a number of AI applications, a reconsideration of traditional training and instructing practices seem to be fundamental to reach a European approach to excellence and trust, as stated by the recent policy recommendations. ${ }^{118}$

\section{Conclusions}

As the conspicuous US robotic surgery litigation has taught us, AI medical applications expose us both to novel legal challenges, namely the duty to instruct and train, as well as sharpening up the existing challenges, making them even more intricate.

In conclusion, even when they cannot be classified as AI high-risk applications, they deeply affect the Product Liability regime. The impact at a European level comes across a proper regulatory framework which is currently under construction and is seeking to respond to the reported challenges. In general terms, the intense activity carried out throughout the most recent years by the European institutions to guide the development of artificial intelligence and robotics in a way that is sustainable, ethically compatible and socially desirable has provided specific guidance on the safety front in order to incentivize the great expansion in a crucial domain such as medicine.

To sum up. Considering the current nature of robotic surgery basically as a teleoperating machine, the issues that arose should be faced from a European perspective in the ongoing evolving path of the Product Liability debate (see section 2). The perspective to revisit the broad definitions and variety of jurisprudential interpretations circulating in the EU regarding product liability will be a proper step further in order to answer to the current robotic surgery challenges. ${ }^{119}$ The notion of the product itself, for example, will need to be updated as more advanced versions of surgical robotics will make the current distinction between product, system, service and performance critical. The increasingly close interaction between products and services makes a clear distinction impossible.

In general, then, the use of artificial intelligence in medicine and embedded in medical tools envisages the expansion of the pool of subjects responsible for the appropriate functioning of the application. The jurist must, therefore, identify the duties of each subject.

For example, the duty to update and monitor the product after it has been placed on the market may no longer be the exclusive responsibility of the manufacturer, where the use of data is controlled by third parties or relies on automated processes. This rescales the role of the manufacturer when a multitude of actors are involved in the design, operation, and use of AI products or systems, or requires expanding the notion of the manufacturer itself to other actors. ${ }^{120}$ Think of the provider who provides the telecommunications service in the facility in which a surgeon operates, since any interruption in service would affect the outcome of the operation. ${ }^{121}$ The plurality of subjects

117. AI Act, p. 29-30 doc.

118. See White Paper on Artificial Intelligence - A European Approach to Excellence and Trust COM(2020) 65 final.

119. These three directories characterized the responsible research and innovation agenda: a key action of the EU Horizon 2020, available at: https://ec.europa.eu/programmes/horizon2020/en/h2020-section/responsible-research-innovation.

120. EU Commission, Report from the Expert Group on Liability and New Technologies, 2019.

121. Although there are no cases involving the latter yet, they are nonetheless of interest, since the adequacy of the telematic link is a necessary component of cyber surgical operations, particularly those of the second type mentioned in the introductory paragraph (those that allow the intervention of a surgeon remotely and even not present in the operating room). This profile is analysed by T. McLean, 'The Complexity of Litigation Associated with Robotic Surgery and Cybersurgery', 3 Int. J. Med. Robotics Comput Assist Surg. (2007), p. 23. 
requires the jurist to identify the exact tasks of each subject and their consequences for a correct apportionment of liability. For the diversity of skills involved, it is logical to think that the lawyer needs the support of various experts to understand exactly the boundaries of the roles of the actors involved. This requires new and interdisciplinary approaches to analyze the subject.

For this reason, the hypothesis - recently set forth by researchers - of the configuration of an 'action of things' seems to be gaining momentum: a feature on the basis of which the most recent doctrine hypothesizes a shift towards a 'responsibility of things', ${ }^{122}$ untied from the traditional category of product responsibility and hinged instead on the concept of defectiveness. After all, this seems to be confirmed by the fact that both the dominant orientation of US case law and the documents of the group of experts appointed by the European Commission are inclined to mitigate the burden of proof required for damages caused by robotic applications, precisely on the grounds of these practical difficulties. The idea to set up a digital ecosystem for AI products seems to be going on the same path in order to facilitate the injured user who came across difficulties in certifying the malfunctioning of a so-called 'smart product'.

Likewise, the European legal debate also accompanies the evolution of the concept of safety, proposing to strengthen and extend the obligation to ensure it in the post-market phase. The primary need is to intensify the duties of surveillance of a product that could perform actions which are not foreseen by the manufacturer based on perceived data from reality (as is the case for a robotic assistant) and from interactions with the environment. It would be appropriate, for instance, to extend the discipline and practice of the producer's observational duties already in use in some of them to the Member States, such as for instance Germany. ${ }^{123}$

Even the new issue regarding the inadequacy of the traditional methods of training personnel reflects some of the required changes, as the information profile is an integral part of the system that guarantees an adequate safety level. As a general remark, an ad hoc education of professionals and end-users is emerging as an undeniable condition for a trustworthy and safe AI ecosystem.

\section{Declaration of Conflicting Interests}

The author(s) declared no potential conflicts of interest with respect to the research, authorship, and/or publication of this article.

\section{Funding}

The author(s) received no financial support for the research, authorship and/or publication of this article. This article has been written in the context of the research activities carried out by the author as a member of the team 'ARrT' and 'FILM 4.0' which operates within the Excellence Project 'Law, Changes and Technologies' of the Department of Legal Sciences of the University of Verona, Italy.

\section{ORCID iD}

Giorgia Guerra (D) https://orcid.org/0000-0002-1097-1703

122. The point recently emerged during the online discussion: Comparative Torts - Liability for Emerging Technologies, organized by the British Association of Comparative Law, on 29 March 2021 between the panellists: André Janssen (Radboud Nijmegen), Professor Ulrich Magnus (Hamburg); Professor Gerhard Wagner (Berlin); Professor Jonas Knetsch (Saint Etienne); Professor Jean Sebastien Borghetti (Paris 2); Dr Colm McGrath (King's College London).

123. Generally speaking the producer's duty towards the community to observe their products and inform it about potential risks is circumscribed to a duty to warn. See J.S. Borghetti, La responsabilité du fait des produits. Etudes de droit compare (LGDJ, 2004). 